\title{
Plastic Origin in Literature: Fyodor Dostoevsky's Novel «Demons»
}

\section{Stepanyan Elena Vladimirovna ${ }^{1}$}

Associate Professor, Moscow State Institute of Culture,

\author{
Moscow, Russia.
}

(date of receiving:, January 2020; date of acceptance: April, 2020)

\begin{abstract}
This article examines the problem of the interaction between literature and fine art. Both prose and poetry have the idiosyncratic power of visualizing the image of the world and man. Significant mention of color and light, the state of the air; the organization of space characteristic of this author; ecstatic inclusions; ways to portray a character; techniques for creating a landscape, interior, and etc. Dostoevsky's representational devices are profoundly symbolic, which is confirmed by the analysis of his novel Demons (1871-1872) showing the presence of a complete ekphrastic episode (Stavrogin's dream of the Golden age inspired by Claude Lorrain's painting) characterizing the anthropology of the writer. The elaborately structured space of the novel reflects the intercrossing of the characters' life paths. References to colors are substantive - for example, the token combination of green and red, which repeatedly appears in the text. An analysis of the descriptions of portraits in the novel allows to conclude that on this level, likewise, a character transpires as a focus of contending forces. Thus, The Demons proves to be a strong example of both literary pictorial art and the writer's search for innovative approaches to depicting the world and man.
\end{abstract}

Keywords: Dostoevsky, Demons, Literature, Representation, Visualization, Portrait, Scenery, Symbol.

1. E-mail: estepanian@ya.ru 


\title{
Пластическое начало в словесности. Роман Достоевского «Бесы»
}

\section{Степанян Елена Владимировна ${ }^{1}$}

Доцент, Московский государственный институт культуры (МГИК),

\author{
Москва, Россия.
}

(дата получения: январь 2020 г.; дата принятия: апрель 2020 г.)

\begin{abstract}
Аннотация
В статье рассматривается проблема взаимодействия литературы и изобразительного искусства. Как проза, так и поэзия обладают специфическими способами визуализации образа мира и человека. Значимы упоминания цвета и света, состояния воздушной среды; организация пространства, характерная для данного автора; экфрастические включения; способы портретирования персонажа; приемы создания пейзажа, интерьера и прочее.

Глубоко символичны изобразительные приемы у Достоевского, что подтверждает анализ романа «Бесы» (1871-1872). Здесь присутствует развернутый экфрастический эпизод (сон Ставрогина о золотом веке, вдохновленный полотном К. Лоррена), характеризующий антропологию писателя. Сложно структурированное пространство романа отображает пересечение жизненных путей героев. Содержательны цветовые упоминания - например, знаковое сочетание зеленого и красного, неоднократно встречающееся в тексте. Анализ портретных изображений в романе позволяет сделать вывод, что и на этом уровне персонаж Достоевского оказывается загадкой, средоточием противоборствующих сил. Таким образом, роман «Бесы» оказывается ярким примером как словесной «живописи», так и поиска писателем новаторских приемов в изображении мира и человека.
\end{abstract}

Ключевые слова: Достоевский, Роман «Бесы», Словесность, Изобразительность, Визуализация, Портрет, Пейзаж, Символ.

1. E-mail: estepanian@ya.ru 


\section{Введение}

Словесность и изящные искусства имеют разное предназначение, задачи, решаемые ими, даже принято противопоставлять друг другу (например, упрек в «литературности» до недавнего времени был одним из самых пренебрежительно-обидных в адрес живописи или скульптуры). Но верно ли это? Специализация, разделение, уточнение и «утончение» проблем, которые стоят перед современными наукой и техникой, свойственны и современному искусству, современному бытию вообще. Однако абсолютизировать такую специализацию невозможно. Слово выражает, образ наглядно являет, слово обращено к слуху, как физическому, так и внутреннему, образ - к зрению. При всей своей специализации, эти способности не разделены в человеческом естестве до какой-то последней автономности друг по отношению к другу. Тут уместно вспомнить знаменитые слова апостола Павла: «... если ухо скажет: я не принадлежу к телу, потому что я не глаз: то неужели оно потому не принадлежит к телу? Если все тело глаз, то где слух? Если все слух, то где обоняние? Но Бог расположил члены, каждый в составе тела, как Ему было угодно. <..> И вы тело Христово, а порознь члены». (I Кор., 12, 16-20, 27). Комментарием к этому апостольскому рассуждению выглядит высказывание, которое сегодня нередко цитируется: «От глубокой древности две познавательные способности почитались благороднейшими: слух и зрение... Эллада возвеличивала преимущественно зрение, Восток же выдвигал как более ценный - слух... никогда не возникало сомнений об исключительном месте в познавательных актах именно этих двух способностей, а потому не возникало сомнений и в первенствующей ценности искусства изобразительного и искусства словесного: это - деятельности, опирающиеся на самые ценные способности восприятия» (Флоренский 1986). Способности восприятия различны, восприятие, в конечном счете, - едино и цельно. (Если это не так, если данные наших чувств противоречат друг другу, налицо болезненный разброд и внутреннее неустройство.) Изображение и слово 
разделены и обращены к разным способностям человека, которые, тем не менее, сохранили тяготение к единству, как сохранила сама человеческая личность стремление к целостности. Личность - индивид, то есть неделимое единство, в том числе единство чувств и способностей.

\section{Основная часть}

Изобразительность неотъемлема от словесности, во всяком случае, до тех пор, пока картина мира продолжает что-то значить для литературы. Это качество проявляется многообразно, и его присутствие говорит о том, как глубоко пластические способы изображения мира усвоены поэзией и прозой. Вообще возникает впечатление, что словесность неуклонно стремилась присвоить себе пластические характеристики и свойства, «аннексировать» чужую территорию, развить собственную изобразительность за счет средств, как будто бы ей не принадлежащих. Причем заимствованные одним видом искусства у другого способь изображения становятся, оказавшись в иной, словесной среде способами выражения. Они усиливают символичность образа, способствуют тому, что он в своей смысловой емкости дорастает до символа. Кроме того, избираемые автором текста изобразительные средства, в конце концов, оказываются еще и характеризующими его человеческую личность, соотносимыми с его биографией. Неслучайно Р. Якобсон говорит о «скульптурной теме» у Пушкина: «Статуя, стихотворение и вообще любое художественное произведение представляют собой особого рода знак. Стихотворение о статуе является, следовательно, знаком знака или образом образа... пушкинская символика проницательно отражает проблемы скульптуры, ... глубоко коренится символика статуи в его творчестве, в жизни поэта...»» (Якобсон 1987. 166). Вследствие этого элементы одного образа прорастают сквозь элементы другого, пластические характеристики, облекаясь в слово, становятся более духовными, слово же - пластически наглядным. 
Попробуем перечислить некоторые из способов изобразительности, используемые литературой. Малая форма, большая форма... уже произнося это, мы, сами того не сознавая, характеризуем литературное произведение не только с точки зрения его объема или его жанровых особенностей, но и с точки зрения того, как оно выглядит. Прежде, чем приступить к чтению, мы видим текст как пусть элементарное, но изображение, какую-то примитивную графику, и это исподволь действует на нас и определенным образом нас настраивает (так, сплошные массивы периодов Пруста даже на беглый взгляд рождают иное зрительское ощущение, чем прихотливо-рваная, перемежающаяся односложными репликами диалогов проза Хемингуэя). Есть подтверждения тому, что писатель нередко отдает себе полный отчет в такой графической выразительности текста и весьма внимательно к ней относится. Вот пример: генеральный директор издательства «Время» Б. Пастернак замечал, что Солженицын видел в печатной странице своего рода арт-объект. Были случаи, когда он долго разглядывал страницу и говорил: «Тут надо бы разрядить абзац, чтобы он не выглядел слишком плотным. Тут приподнять немного строчку». «Он воспринимает книгу еще и на глаз, как графическое произведение», - заключал собеседник писателя (Кучерская 2006).

И если так видит свой текст прозаик, то в стихотворении вообще нет детали, которая не была бы графически значима. Орфография, пунктуация (или ее отсутствие), стихотворный размер и длина текста, разбивка на строфы, прописная или строчная буква в начале строки - каждый из этих элементов играет определенную роль. Тому, что поэт воспринимает свое произведение и как графическое, изобразительное единство, существуют весомые свидетельства. Пропущенные строфы в «Онегине», замененные столбцами точек, стихотворная «лесенка» и ахматовская строфа, фигурные стихи разного рода и разных эпох - все это широко известные примеры, показывающие, как литературное содержание изнутри себя продуцирует 
«картинку», как бы диктует тексту то визуальное впечатление, которое от него неотъемлемо.

Есть и еще один способ существования изобразительной стихии в литературе: произведение может повествовать о судьбе художника - таковы «Портрет» Гоголя, чеховский «Дом с мезонином». «Портрет» целиком посвящен теме последнего суда над художественным творчеством, верности или измены мастера своему призванию, а в «Доме с мезонином» «пейзажи», которые пишет главный герой и о которых несколько раз упоминается, ничего не меняют в происходящем, - они только акцент, усиливающий мотив его странничества, его бродячей, бесприютной судьбы. Но в обоих случаях «жизнь художника» оказывается основой сюжета, почвой для авторской идеи. В качестве симметричных примеров, относящихся к миру изобразительного искусства, вспомним классические писательские портреты работы Кипренского, Репина, Крамского, Петрова-Водкина или Альтмана. Мы не только знаем, что здесь изображены «люди литературы» с печатью их особенного призвания, мы прочитываем это. Бронзовое изображение музы Эрато за плечом Пушкина в его портрете; пишущий Толстой или Толстой, устремивший свой знаменитый пронзительный, исследующий взгляд на зрителя, - язык портрета настойчиво и ясно говорит о литературном призвании, не стесняясь откровенно-повествовательных подробностей.

Литература, как видим, разными путями проникает на территорию изобразительного искусства и возвращается к себе с богатой добычей. Факт «избирательного сродства» между словесностью и пластическими искусствами налицо.

Словесные и пластические искусства существовали и продолжают существовать в сложном взаимодействии, соприкасаясь друг с другом. В своих работах о. Павел Флоренский говорит о том, как словесность, свободная от схематизма, и изобразительное искусство, свободное от иллюзионизма, 
пробивают бреши в окружающей действительности и обнаруживают ее духовный смысл. Это доступно, по мысли автора, только истинному реализму. Следовательно, не только происхождение, но и устремленность, и цель у литературы и изобразительного искусства, в конце концов - общие. Возможно найти некую общность и между их методами и приемами. В самом деле: какого бы крупнейшего художника слова мы ни взяли, мы обнаружим в его творчестве присутствие того, что можно назвать изобразительностью.

Безусловно, сказанное относится к прозе Достоевского. Этот писатель - при отсутствии у него той традиционной литературной пластичности, наглядности, живописности, которые имеются, например, у Тургенева и Гончарова, или скульптурности, которая характерна для Толстого (не этот ли а-пластицизм и затрудняет перевод Достоевского на кино- и театральный язык, хотя попытки такого рода были и будут многочисленны), - этот писатель с какой-то выразительной скупостью пользуется своими изобразительными средствами.

В все же средства эти многообразны, каждое из них находит себе применение как вообще в текстах Достоевского, так и конкретно - в том или ином произведении, где оно может раскрыться с особой полнотой. Среди них следует упомянуть следующие: семантика и частотность цветовых упоминаний (например, роль желтого и красного цветов в тексте «Преступления и наказания», зеленые «сигналы» и их значение в тексте «Идиота»); своеобразная портретность героев писателя (об этом мы скажем чуть ниже); особенный, активно характеризующий героя, «говорящий» аксессуарный ряд; наконец, «функция смотрения», свойственная персонажам романов Достоевского (так, «романом ви́дения» можно назвать, например, «Подростка», герои которого по-разному смотрят на мир и друг на друга, причем угол зрения каждого из них обнаруживает нечто сокровенное в каждом характере.) Сюда же относятся значимые упоминания имен художников и названия, а также описания живописных шедевров, благодаря которым в 
текстах рождаются особые зоны смыслового напряжения. (В науке уже имеются замечательные и многочисленные наблюдения, например, над рафаэлевским или лорреновским кодами у Достоевского. Так, благодаря впечатлению от «Пейзажа с Ацисом и Галатеей» французского художника XVII века Клода Лоррена, полученному Достоевским в Дрезденской галерее, формируется образ идеального «золотого века», блаженного детства человечества, неоднократно возникающий в текстах писателя и являющийся одним из смысловых центров его философии истории и антропологии.) Следует упомянуть и особую пространственность прозы Достоевского, - роль пространства в его текстах, то, что оно «изоморфно времени», неоднократно отмечалось в науке. Упоминание топонимов, рождающее в сознании читателя те или иные зрительные образы, как бы маркирует не только места пребывания, но и разные периоды прошлого героев, этапы их становления (пребывание в швейцарской лечебнице князя Мышкина, московское детство героя «Подростка» Аркадия Долгорукого и проч.)

Вернемся к такому средству текстовой изобразительности, как упоминание Достоевским живописных шедевров и их авторов. «Бесы»- роман, как известно, включающий большой «лорреновский» эпизод (сон Ставрогина заграницей о золотом веке. Этот образ, встречается, как говорилось выше, и в других произведениях писателя, - в «Подростке», «Сне смешного человека»). Есть там и выразительные упоминания в соответствующих контекстах имен Рафаэля и Теньера (Тенирса). Тем не менее можно утверждать, что «Бесы» менее изобразительны, менее пластичны, чем, например, «Преступление и наказание» или «Идиот» (хотя, повторю, тут речь идет о специфической «достоевской» пластичности). Но, быть может, тем интереснее проследить, какими именно изобразительными приемами пользуется здесь автор.

Посмотрим на его портреты, пейзажи и интерьеры. Они взрывчаты, как вообще взрывчата проза этого писателя, они подготавливают большие 
столкновения между персонажами и большие взрывы его финалов. Можно сказать, что, как и в сюжетостроении, и в характерологии Достоевского, визуально-изобразительный план его романов богат неожиданностями и противоречиями. В чем же противоречивость, своеобразная «конфликтность» таких описаний?

Характерно, что в подобных описаниях у Достоевского существенную роль играет противительный союз «но» (иногда только подразумеваемый), или слово (группа слов), заменяющая его. Классический пример - портрет Ставрогина, с итоговым выводом: «... казалось бы, писаный красавец, а в то же время как будто и отвратителен» (Достоевский 1974. 37). (Заметим, что своего рода союз «но» помещен - а вернее, подразумевается писателем - и между этим и двумя другими портретами героя: в отрочестве он - бледный и тихий, впоследствии же представляется повествователю уже красавцем в полном смысле слова, человеком недюжинной силы. Портреты одного и того же персонажа противопоставлены друг другу). Кроме того, многозначительно упоминание о маскообразности черт героя, а в другом месте романа - о том, что он в состоянии полусна как бы оцепенел и напоминал статую. В авторских указаниях такого рода также заключена противоречивость, - герой жив и физически развит, но в то же время не жив, духовно умер или при смерти. Перед нами - своего рода «жизнь-в-смерти», как называл такое фантомное состояние Кольридж.

Буквально то же можно сказать о других центральных персонажах романа: Лиза - так сказать, красавица по самому своему романному амплуа, по предназначению и роли, так - причем с прописной буквы - она именуется и в подготовительных материалах к роману. А между тем, замечает наблюдательный рассказчик, она вовсе не красавица, она «худа, скулиста, глаза поставлены как-то по-калмыцки криво» (Достоевский 1974. 88); в облике Лебядкиной детскость, «тихая радость» взгляда и улыбки, то есть высшая 
естественность, противоречат прямым указаниям на убожество, на убогие ее прикрасы - белила, румяна и пр. Неуклюжесть и «шершавость» Шатова (в первую очередь - физическая, внешняя) сразу же восполняются указаниями на его деликатность и стыдливость. «Черные без блеску» глаза теоретического самоубийцы Кириллова - указание на погруженность в себя, на то, что этот человек «не отражает» окружающего мира, невосприимчив к свету дня. В то же время он смело сидит в седле, подчиняет себе лошадь, - он способен к проявлению силы и воли, он предназначен для жизни, от которой отказывается из принципа, из теоретического убеждения.

Россыпь противительных «но» обнаруживается в портрете Петра Верховенского: «одетый по моде, но не щегольски... не дурен собой, но лицо его никому не нравится... выражение лица словно болезненное, но так только кажется» и т. д. Словом, мнимость на мнимости, все, непосредственно наблюдаемое в этом человеке, недостоверно. Достоверным, вполне утвердительным является одно только определение, именно то, с которым наблюдатель обращается к читательскому воображению: «вам как-то начинает представляться, что язык у него во рту... какой-нибудь необыкновенно длинный и тонкий, ужасно красный и с чрезвычайно вострым, беспрерывно и невольно вертящимся кончиком» (Достоевский 1974. 113-114). Тут повествователь обращается непосредственно к читательской фантазии, из-за чего рождается вихрь ассоциаций: и змея, выползающая из черепа Олегова коня, и piccola bestia самого Достоевского, упоминаемая и в «Дневнике писателя», ночной кошмар Ипполита из «Идиота», и цитата из одной из «Ричарда II» Шекспира, где король в гневе говорит неугодному вельможе: твой болтливый язык, «вертящийся в твоей башке».

Можно назвать портретные характеристики, подобные вышеупомянутым, «вихревыми», движущимися - благодаря тому внутреннему беспокойству, противоборству сил, «неравности человека самому себе», которые мы 
замечаем и в самих персонажах, и в их портретах. Всё и все является и являются не вполне тем, чем кажется (кажутся), всё богато неожиданностями. Они заставляют вспомнить и известные рассуждения Шиллера о «грации и достоинстве»: грация, иными словами - динамичное начало превалирует в портрете героев русского писателя, она существеннее традиционных портретных черт, описательности, чисто физических характеристик. (Кстати, наиболее пластически подробен и традиционно портретен второстепенный персонаж Федька Каторжный. В его описании присутствует вполне традиционная для словесного искусства изобразительная деталировка. А между тем именно он заявляет, что и он «не равен самому себе»: «а я, может, по вторникам да по средам только дурак, а в четверг и умнее его» (Достоевский 1974. 205), то есть формулирует один из основных законов характерологии Достоевского: человек сложен потому, что неожидан.)

Нечто подобное - имеется в виду взрывчатость, противоречивость свойственны и состояниям природы, и взаимодействиям природы и человека: это обнаруживается в пейзажах «Бесов». Пейзаж здесь совсем эскизен, едва намечен. Однако идиллический намек на поэзию весенней ночи в имении Скворешники («Май был в полном расцвете. Зацвела черемуха... легкие, как пух, белые облачка, скользившие вокруг ясного месяца»), в мгновение ока исчезает при появлении героини - Варвары Петровны, больше всего напоминающей в эту «майскую ночь» «утопленницу»: «желтое лицо ее почти посинело, губы были сжаты...» (Там же. 18). Роковое утро гибели Лизы обозначено, казалось бы, проходной, а все же оксюморонной фразой: «Наступил... угрюмый, мрачный рассвет» (Там же. 413). Пышный закат солнца над горой Острой, о котором вспоминает Марья Лебядкина, тут же, без переходов, сменяется в ее описании быстро движущейся и все покрывающей тенью.

Вспомним также, что литературный пейзаж может воссоздаваться в читательском сознании (пусть даже точечно, на секунду) благодаря самым 
беглым упоминаниям того или иного географического пункта, даже оставаясь за кадром повествования. В романе Достоевского от подобных упоминаний возникает что-то вроде пространственной сутолоки, географического столпотворения: маршруты молодого Ставрогина за границей в пределах одной фразы описывают параболу от Иерусалима до Исландии. От него не отстают другие персонажи - малоподвижная, больная ногами Прасковья Ивановна Дроздова торопится из Парижа в Верне-Монтре; тут же Варвара Петровна с Дашей подхватываются и через Париж (а никак не напрямую) отправляются туда же. Возникает - от одного перечисления географических названий, обозначающих пункты пребывания героев - специфическое напряжение пространства, через которое к героям и к читателям доносится «будущего зов». Здесь звучит авторский намек не только на то, что с ними уже произошло, но пока еще от читателя скрыто, но и на то, что они еще переживут, - великий хаос, неразбериху отношений, вообще «смуту», которую грозится «пустить» заговорщик и провокатор Петр Верховенский..

Еще более замечательны интерьеры в «Бесах». Не станем останавливаться на них подробно, обратим внимание только на две бытовые, интерьерные детали. Это - свеча на окошке в домике Лебядкиных и всегдашний чай на столе у Кириллова. Рискнем предположить, что они здесь играют ту же примерно роль, что и союз «но» (и заменяющие его слова) в портретных описаниях. Они тоже расположены на острие противоречий, где встречаются противоположные, но встречно направленные силы. Нет смысла распространяться здесь о символике свечи в искусстве, но, так или иначе, свеча здесь - и маяк, указывающий путь, и крошечный источник тепла, света, атмосферы какой-то хоть минимальной домашности, намека на уют. И именно она указывает путь палачу к жертве, бесприютно странствующему преступнику - к русской юродивой, которая его и обличит, и отвергнет. Свеча соединяет, но соединяет противников. Чай, кипящий самовар - эта деталь 
напоминает о необходимом консерватизме жизни, о ее укладности, бытовой упорядоченности (причем так бывает и в трагических ситуациях - у Достоевского в частности, хотя и не только у него, - вспомним появление «самоварчика» и рассуждения героя-повествователя по этому поводу после сцены самоубийства Оли в «Подростке»). Возвращаясь к Кириллову, заметим: чай, сахар, хлеб на столе у теоретического самоубийцы говорят нам, конечно, о его ночных бдениях и философских судорогах, но и являются чем-то вроде малых, скромных посланцев «жизни, как она есть», той жизни, которую идеалист Кириллов, без сомнения, любит и которую отдает путем чудовищного насилия над собой. Характерно и то, что у Кириллова пьют чай именно его будущие убийцы - теоретик Ставрогин, практик Верховенский. Самое мирное, самое консервативно-обывательское, семейное даже занятие, самая смиренная бытовая деталь - кипящий чай - соединяют в «кирилловских» сценах убийц и жертву.

И, наконец, об одной колористической характеристике текста «Бесов». Проснувшись после своего «лорреновского» сна о золотом веке, Ставрогин видит в закатных лучах красного паучка на листке герани. Колористически это сочетание - алого и зеленого - так богато, что оно во всей полноте возможно только в природе, или - и то далеко не всегда - в произведениях высокого искусства. Ставрогинское впечатление следует за его сном (обычно же бывает наоборот: мельчайшее впечатление дня может разрастаться в сонное видение, картину с сюжетом). Во всяком случае, перед его глазами - сочетание, говорящее и о силе жизни во всем богатстве ее красок, и о невинности природы: алый паучок оттеняет свежую зелень листа. (Только в сознании и в жизненной практике Ставрогина, из его деяний могут родиться жуткие фантазмы вроде огромного паука, которого прозревает за спиной Николая Всеволодовича Лиза Тушина.) Упомянутая цветовая гамма снова возникает в сцене пожара, на который смотрит Лиза, одетая в светлозеленое платье с 
кружевами и в красную шаль (кстати, сочетание, вдохновившее М. Добужинского на создание красивейшей из его декораций к «Николаю Ставрогину» - инсценировке «Бесов» в Московском художественном театре). Если прибавить к упомянутому двуцветию упоминаемый в конце романа туман за окном, туман, по которому двинутся в свое последнее путешествие и Лиза, и Степан Трофимович, то получим сочетание белого, зеленого и красного, то есть самую богатую и полную цветовую рифму, на символическом языке говорящую нам о полноте бытия, напоминающую, что на самом деле «жизнь есть рай» и «золотой век в кармане» (формулы человеческого братства и всеобщей любви, к которым Достоевский прибегает как в своих художественных, так и в публицистических произведениях), Это то, мимо чего прошли ослепленные герои «Бесов».

\section{Заключение}

Таким образом, изобразительность текстов Достоевского, специфичная, резко отличающаяся от традиционной словесной изобразительности, несомненно существует, и роман «Бесы» является наглядным свидетельством этого. Как мы видели, визуализация достигается в тексте разными способами и при использовании различных средств. Цветовые, пространственные акценты, динамизация и противоречивость портрета одного и того же персонажа, световоздушная среда и пейзаж, характер интерьера и предметные детали не просто придают фактурность действию и лицам романа, но оказываются символическими характеристиками происходящего в этом «романепредсказании», как принято называть «Бесы» в достоевистике.

\section{Литература}

1- Достоевский Ф.М. (1974). Бесы. // Полное собрание сочинений в тридияати mомах. Т. 10. -Л.: Изд-во «Наука». 
2- Кучерская М. (2006), Исправленному поверят. Александр Солженицын представит собрание сочинений. // Ведомости, 16. 11. № 216 (1743).

3- Флоренский П.А. (1986). Итоги. //Эстетические ценности в системе культуры. URL: http:www.humanities.edu.ru

4- Якобсон Роман. (1987). Работы по поэтике. -М.: Изд-во «Прогресс».

\section{Bibliography}

1- Dostoevskij F.M. (1974). Besy. // Polnoe cobranie sochinenij v tridcati tomah. T. 10. -L.: Izd-vo «Nauka».

2- Kucherskaja M. (2006), Ispravlennomu poverjat. Aleksandr Solzhenicyn predstavit sobranie sochinenij. // Vedomosti, 16. 11. № 216 (1743).

3- Florenskij P.A. (1986). Itogi. //Jesteticheskie cennosti v sisteme kul'tury. URL: http:www.humanities.edu.ru

4- Jakobson Roman. (1987). Raboty po pojetike. -M.: Izd-vo «Progress».

\section{HOW TO CITE THIS ARTICLE}

Степанян Е. В. (2020). Plastic Origin in Literature: Fyodor

Dostoevsky's novel «Demons». Issledovatel'skiy Zhurnal

Russkogo Yazyka i Literatury, 8(2), 187-202.

DOI: $10.29252 /$ iarll.16.195

URL: http://journaliarll.ir/index.php/iarll/article/view/133

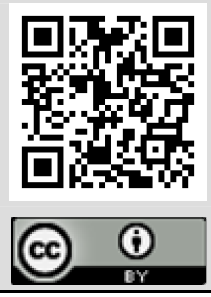


عناصر زيباشناختى در گفتار: بر اساس رمان (جنزدگان) داستايفسكى

$$
\begin{aligned}
& \text { يلنا ولاديمير اونا استيِانيان' }
\end{aligned}
$$

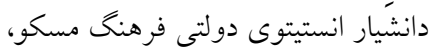

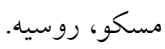

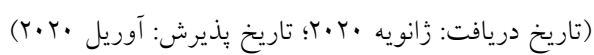

جִكيده

در مقالهٔ حاضر به موضوع ارتباط و تعامل ميان ادبيات و هنرهاى تجسمى يرداخته مى شود.

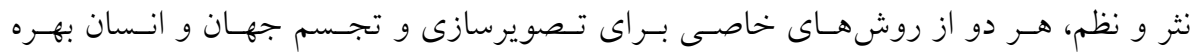

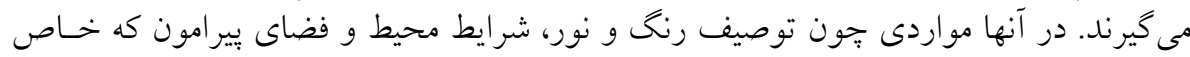

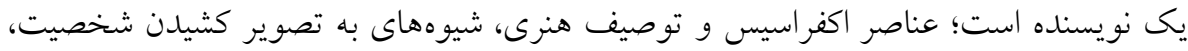

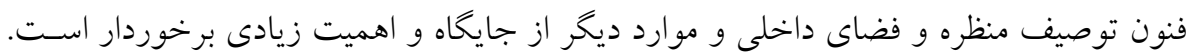
با مطالعه و تحليل رمان (اجنزدكان) داستايفسكى (AVY)

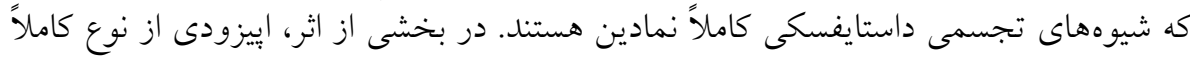

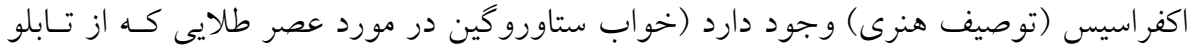

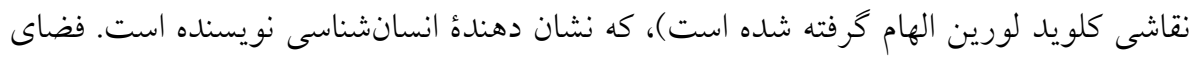

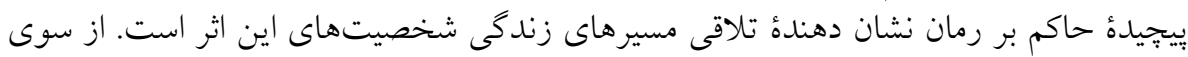

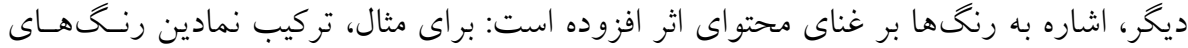

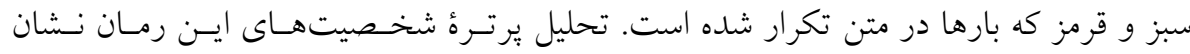

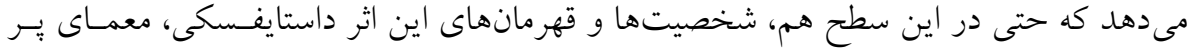

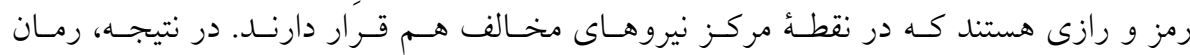

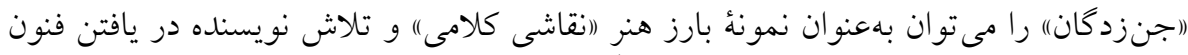

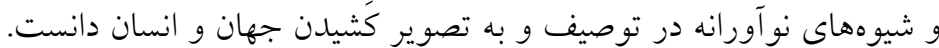

وازگًان كليدى: داستايفسكى، رمان (جنزدگًان)، كلام، تجسم، تـصويرسازى، يرتسره و تسصوير شخصيت ها، منظره، نماد. 